\title{
Effect of intermittent administration of teriparatide on the mechanical and histological changes in bone grafted with $\beta$-tricalcium phosphate using a rabbit bone defect model
}

\author{
JUN KOMATSU ${ }^{1}$, NANA NAGURA ${ }^{1}$, HIDEAKI IWASE $^{2}$, MAMORU IGARASHI $^{3}$, \\ OSAMU OHBAYASHI ${ }^{4}$, ISAO NAGAOKA ${ }^{3}$ and KAZUO KANEKO ${ }^{1}$ \\ ${ }^{1}$ Department of Medicine for Motor Organs, Juntendo University Graduate School of Medicine, \\ Tokyo 113-8421; ${ }^{2}$ Department of Bio-Engineering, Juntendo University Institute of Casualty Center, \\ Izunokuni, Shizuoka 410-2295; ${ }^{3}$ Department of Host Defense and Biochemical Research, \\ Juntendo University Graduate School of Medicine, Tokyo 113-8421; ${ }^{4}$ Department of Orthopaedic \\ Surgery, Juntendo University Shizuoka Hospital, Izunokuni, Shizuoka 410-2295, Japan
}

Received February 2, 2016; Accepted February 10, 2017

DOI: $10.3892 /$ etm.2017.5424

\begin{abstract}
Grafting $\beta$-tricalcium phosphate (TCP) is a well-established method for restoring bone defects; however, there is concern that the mechanical stability of the grafted $\beta$-TCP is not maintained during bone translation. Teriparatide has an anabolic effect, stimulating bone formation and increasing bone mineral density for the treatment of osteoporosis. The aim of the present study was to evaluate the effect of intermittent teriparatide treatment on changes in bone grafted with $\beta$-TCP using a rabbit bone defect model. Bone defects $(5 \times 15 \mathrm{~mm})$ were created in the distal femoral condyle of Japanese white rabbits, and $\beta$-TCP granules of two different total porosities were manually grafted. Teriparatide $(40 \mu \mathrm{g} / \mathrm{kg})$ or $0.2 \%$ rabbit serum albumin solution as a vehicle control was subcutaneously injected three times per week following the surgery. At 4 or 8 weeks post-surgery, serum samples were obtained and the levels of $\gamma$-carboxylated osteocalcin (Gla-OC) were quantified using ELISA. Histomorphometry was also performed using sections of graft sites following staining for tartrate resistant acid phosphatase. Activity and mechanical strength (maximum shear strength, maximum shear stiffness and total energy absorption) were evaluated using an axial push-out load to failure test. Teriparatide treatment significantly increased $(\mathrm{P}<0.05)$ the serum levels of Gla-OC, a specific marker for bone formation, suggesting that teriparatide enhances bone formation in $\beta$-TCP-grafted rabbits. Furthermore teriparatide increased the degradation of
\end{abstract}

Correspondence to: Professor Isao Nagaoka, Department of Host Defense and Biochemical Research, Juntendo University Graduate School of Medicine, 2-1-1 Hongo, Tokyo 113-8421, Japan

E-mail: nagaokai@juntendo.ac.jp

Key words: teriparatide, $\beta$-tricalcium phosphate, bone graft, bone metabolism, mechanical strength
$\beta$-TCP by bone remodeling $(\mathrm{P}<0.05)$ and promoted the formation of new bone following application of the graft compared with the control group $(\mathrm{P}<0.01)$. Furthermore, teriparatide suppressed the reduction in mechanical strength $(\mathrm{P}<0.05)$ during bone translation in bone defects grafted with $\beta$-TCP. The results of the present study demonstrate that teriparatide is effective in maintaining the mechanical stability of grafted $\beta$-TCP, possibly by promoting new bone formation.

\section{Introduction}

In an aging society, hip, knee and shoulder replacement surgeries, as well as vertebrae fusion in spinal surgeries, are increasing in prevalence. Bone graft is essential, particularly for fusion in spinal surgery $(1,2)$ and augmentation in revision arthroplasty (3-5), Bone grafting consists of filling the bone defect with a material to support new bone formation, and enhance healing and successful fusion of defects or nonunions $(6,7)$.

Autograft, allograft and synthetic ceramics are used as materials for bone grafting. Iliac crest bone autograft is considered the gold standard for orthopedic surgery (6-8), as a sufficient amount of cancellous bone obtained from the pelvis exhibits all the desired properties of osteoconduction, osteoinduction and osteogenicity. Furthermore, the use of autologous bone has merits, including a lack of ethical issues, no concerns for disease transmission and no risk of immunogenicity. However, the autograft procedure requires an additional surgery to collect the bone for grafting, which may lead to complications such as paresthesia, long-lasting pain, hematoma and infection $(9,10)$.

Allograft bone is harvested from tissue donors. Compared with the bone graft substitutes (synthetic ceramics) in use today, allograft bone is relatively inexpensive and readily available. Furthermore, it retains substantial structural strength and carries no associated donor site morbidity. However, the incorporation of allograft into the host bone is slower and less complete compared with autograft (11). In addition, 
there is a theoretical risk of disease transmission and immune rejection (10).

Synthetic bone graft substitutes are osteoconductive agents that consist of hydroxyapatite and $\beta$-tricalcium phosphate $(\beta$-TCP), or a combination of these materials $(12,13)$. Hydroxyapatite is a naturally occurring mineral form of calcium apatite with the formula $\mathrm{Ca}_{5}\left(\mathrm{PO}_{4}\right)_{3}(\mathrm{OH})$, and possesses the properties of biocompatibility and osteoconductivity $(14,15)$. However, it has various disadvantages, such as remaining in the body for a long time and showing no progressive bone formation in the course of bone tissue repair (16). By contrast, $\beta$-TCP is a synthetic porous ceramic graft material composed of tricalcium phosphate [TCP; $\left.\mathrm{Ca}_{3}\left(\mathrm{PO}_{4}\right)_{2},\right]$, which comprises $70 \%$ of human bone (17-21). During the bone remodeling process, $\beta$-TCP is gradually degraded by osteoclastic resorption and finally replaced with mature host bone $(22,23)$. Thus, $\beta$-TCP is a highly biocompatible material that provides a resorbable interlocking network within a bone defect (24). However, $\beta$-TCP must be protected from excessive loading forces until a solid fusion has taken place, due to its brittle structure and low tensile strength (23,25-27).

Parathyroid hormone $(\mathrm{PTH})$ is a peptide hormone consisting of 84 amino acids that is involved in calcium homeostasis; its secretion from the parathyroid gland is mainly controlled by serum $\mathrm{Ca}^{2+}$ through negative feedback (28). Teriparatide is a biologically active fragment containing the N-terminal 34 amino acids of human parathyroid hormone (hPTH), and daily and weekly teriparatide administration has been approved for the treatment of osteoporosis $(29,30)$. When teriparatide is administered intermittently, it has an anabolic effect on osteoblasts, thereby stimulating bone formation and increasing bone mineral density (31,32). In 1999, Andreassen et al (33) reported the efficacy of intermittent administration of teriparatide in a rat tibial fracture model. Teriparatide was demonstrated to promote bone formation by increasing the number and activity of osteoblasts, enhancing the mean cortical thickness and trabecula volume, and improving bone microarchitecture, thereby increasing fracture strength and callus quantity. Similarly, intermittent administration of teriparatide has previously been demonstrated to increase the volume, stiffness, torsional strength and density of fracture calluses in a rat femur fracture model $(34,35)$. These observations suggest that teriparatide enhances and accelerates not only osteogenesis but also bone remodeling in the process of bone repair $(36,37)$.

The aim of the present study was to investigate whether intermittent administration of teriparatide with low frequency (three times per week) enhances the remodeling of bone defects grafted with $\beta$-TCP, using a rabbit bone defect model, based on radiographic and histological examinations, and mechanical testing.

\section{Materials and methods}

Preparation of $\beta$-TCP. In the present study, two types of $\beta$-TCP granules with a total porosity of $67 \%$ (KG-2) and 75\% (KG-3) were supplied by HOYA Corporation (Tokyo, Japan). $\beta$-TCP granules contain three types of pores: Macropores (diameter, 100-300 $\mu \mathrm{m}$ ), interconnected pores (diameter, 50-100 $\mu \mathrm{m}$ ) and micropores (diameter, $0.5-10 \mu \mathrm{m}$ ). $\beta$-TCP slurry was produced by HOYA Corporation by mixing dibasic calcium phosphate and calcium carbonate, and milled with water (quantities not known); the slurry was subsequently sintered and dried to produce $\beta$-TCP powder, which was burnt at $1,100^{\circ} \mathrm{C}$ with surfactant and bubbled stabilizer (types not known) to produce $\beta$-TCP granules containing three types of pores (macropore, interconnected pore and micropore). The compressive strength is $15 \mathrm{MPa}$ for $67 \%$ porosity and $1.5 \mathrm{MPa}$ for $75 \%$ porosity.

Teriparatide. Teriparatide, also known as hPTH (1-34), corresponds to the N-terminal part of hPTH, the full length of which is 84 amino acids (38). Teriparatide acetate was supplied by Asahi Kasei Pharma Corp. (Tokyo, Japan), dissolved in $0.2 \%$ rabbit serum albumin solution (Sigma-Aldrich; Merck $\mathrm{KGaA}$, Darmstadt, Germany), and stored at $-30^{\circ} \mathrm{C}$ until use.

Bone defect model. The present study was approved by the Ethics Committee of Juntendo University Institute of Casualty Center (Juntendo University Shizuoka Hospital, Izunokuni, Japan). A total of 60 male Japanese white rabbits (12 weeks old; 3.5 kg; Japan SLC, Inc., Hamamatsu, Japan) were divided into 10 groups: Sham group for 4 weeks; $67 \% \beta$-TCP without teriparatide for 4 weeks; $67 \% \beta$-TCP with teriparatide for 4 weeks; $75 \% \beta$-TCP without teriparatide for 4 weeks; $75 \%$ $\beta$-TCP with teriparatide for 4 weeks; Sham group for 8 weeks; $67 \% \beta$-TCP without teriparatide for 8 weeks; $67 \% \beta$-TCP with teriparatide for 8 weeks; $75 \% \beta$-TCP without teriparatide for 8 weeks; and $75 \% \beta$-TCP with teriparatide for 8 weeks. The rabbits were housed separately in standard cages in a temperature-controlled room $\left(24 \pm 3^{\circ} \mathrm{C}\right.$ and humidity of $\left.55 \pm 15 \%\right)$ with a 12-h light/dark cycle, fed a commercial standard diet (NR-2; Nisseiken Co. Ltd., Tokyo, Japan) and received drinking water ad libitum.

Rabbits were anesthetized with an intravenous bolus injection of $25 \mathrm{mg} / \mathrm{kg}$ sodium pentobarbital (Somnopentyl; Kyoritsu Seiyaku Corporation, Tokyo, Japan) prior to surgery. The distal metaphysis and lateral condyle of the femur were exposed through a $2-\mathrm{cm}$ lateral longitudinal incision, and the thigh muscles were divided under sterile conditions. The bone membrane was removed and a dead-end defect $(5 \mathrm{~mm}$ in diameter and $15 \mathrm{~mm}$ in depth) was created in the lateral cortex just proximal to the epiphyseal plate using an air drill with an intermittent drip of sterile saline to control the temperature. The orientation of the bone defect was perpendicular to the sagittal axis of the femur.

$\beta$-TCP granules $(70 \mathrm{mg}$ of those with $75 \%$ porosity or $80 \mathrm{mg}$ of those with $67 \%$ porosity) respectively, were manually grafted into the defected hole $(5 \mathrm{~mm}$ in diameter and $15 \mathrm{~mm}$ in depth corresponding to a volume of $294 \mathrm{~mm}^{3}$ ). The soft tissue was closed in layers. All procedures were performed by the same surgeon. Following the completion of surgery, teriparatide $(40 \mu \mathrm{g} / \mathrm{kg})$, or $0.2 \%$ rabbit serum albumin solution as a vehicle control, was subcutaneously administered to rabbits in the PTH and Control groups of animals, respectively, three times per week. In some experiments, the bone defect was created in the distal metaphysis and lateral condyle of the femur and no $\beta$-TCP granules were grafted. These animals were subcutaneously injected with $0.2 \%$ rabbit serum albumin solution three times per week and used as the Sham group.

At 4 or 8 weeks post-surgery, rabbits were anesthetized via the intraperitoneal injection of $50 \mathrm{mg} / \mathrm{kg}$ pentobarbital 
sodium. Rabbits were sacrificed by exsanguination via the femoral vein under deep anesthesia. Death of the animals was confirmed by cardiac arrest and cessation of respiration. Blood samples were harvested from the femoral vein, and the serum was separated by centrifugation at $1,220 \mathrm{x}$ g for $20 \mathrm{~min}$ at $4^{\circ} \mathrm{C}$ and stored at $-80^{\circ} \mathrm{C}$. Following sacrifice, femurs was collected from every rabbit.

In order to evaluate bone formation and remodeling in vivo, all rabbits were subcutaneously injected twice with calcein, a calcium-binding fluorescent dye $(10 \mathrm{mg} / \mathrm{kg}$; Wako Pure Chemical Industries, Ltd., Osaka, Japan) on days 3 and 10 prior to sacrifice.

Assay of Gla-osteocalcin. Serum levels of Gla-osteocalcin (Gla-OC) were measured using an ELISA kit (Gla-OC EIA kit; Takara Bio, Inc., Shiga, Japan) as previously described $(38,39)$.

Radiological analysis \& measurement of bone mineral density (BMD). Distal femoral condyles containing graft sites were dissected from the femurs, and X-ray images were captured using micro computerized tomography (CT) with a SkyScan 1172 instrument (Bruker microCT, Konitich, Belgium) to evaluate the absorption of $\beta$-TCP and new bone formation. BMD values at the femoral condyle graft sites were calculated from micro-CT images using Image Pro (version 7; Media Cybernetics Inc., Rockville, MD, USA) with reference to BMD phantom.

Histological analyses. Distal femoral condyles containing the graft sites were fixed in $4 \%$ formaldehyde in $0.1 \mathrm{M}$ phosphate buffer ( $\mathrm{pH} 7.2$ ) at $4^{\circ} \mathrm{C}$ for $20 \mathrm{~h}$ and subsequently dehydrated with $70 \%$ alcohol, embedded in 2-hydroxyethyl methacrylate/methyl methacrylate/2-hydroxyethyl acrylate mixed resin, and cut into $3-\mu \mathrm{m}$ sections, as previously reported (40-42). These sections were stained with Giemsa. Alternatively, the sections were histochemically stained for tartrate resistant acid phosphatase (TRAP) activity and counterstained with hematoxylin and nuclear fast red (43). Histomorphometric analyses were performed using BIOREVO (Keyence, Osaka, Japan), and Image Pro (version 7), and the graft sites of femoral condyles were analyzed in a region $(0.55 \times 2.2 \mathrm{~mm})$, which was centrally aligned in a created bone defect. The quantitative histomorphometric analysis of trabecula remodeling was performed according to the following stereologic calculations (44); i) bone volume (BV)/tissue volume (TV; $\%$ ); ii) mineralized surface (MS)/bone surface[BS; \%; (double labeled surface+single labeled surface/2)/BS]; iii) mineral apposition rate (MAR; $\mu \mathrm{m} /$ day; interlabel thickness/interlabel time); iv) bone formation rate (BFR) $/ \mathrm{BS}\left(\mu \mathrm{m}^{3} / \mu \mathrm{m}^{2} /\right.$ year; MAR x MS/BS); v) osteoclast number (N.Oc)/BS (N/mm); vi) osteoclast surface (Oc.S)/BS (\%); and vii) osteoid surface (OS)/BS (\%). Furthermore, the change in $\beta$-TCP volume in the graft was evaluated using the following parameters; viii) $\beta$-TCP volume (TCPV)/TV (\%); and ix) newly formed bone volume (BV-TCPV)/TV (\%).

MAR was measured by calculating calcein-labeling under a fluorescence microscope with excitation and emission wavelengths of 495 and $515 \mathrm{~nm}$, respectively. BV/TV, MS/BS, MAR, BFR/BS, TCPV/TV and (BV-TCPV)/TV were calculated using Giemsa-stained sections. An osteoclast was defined as a
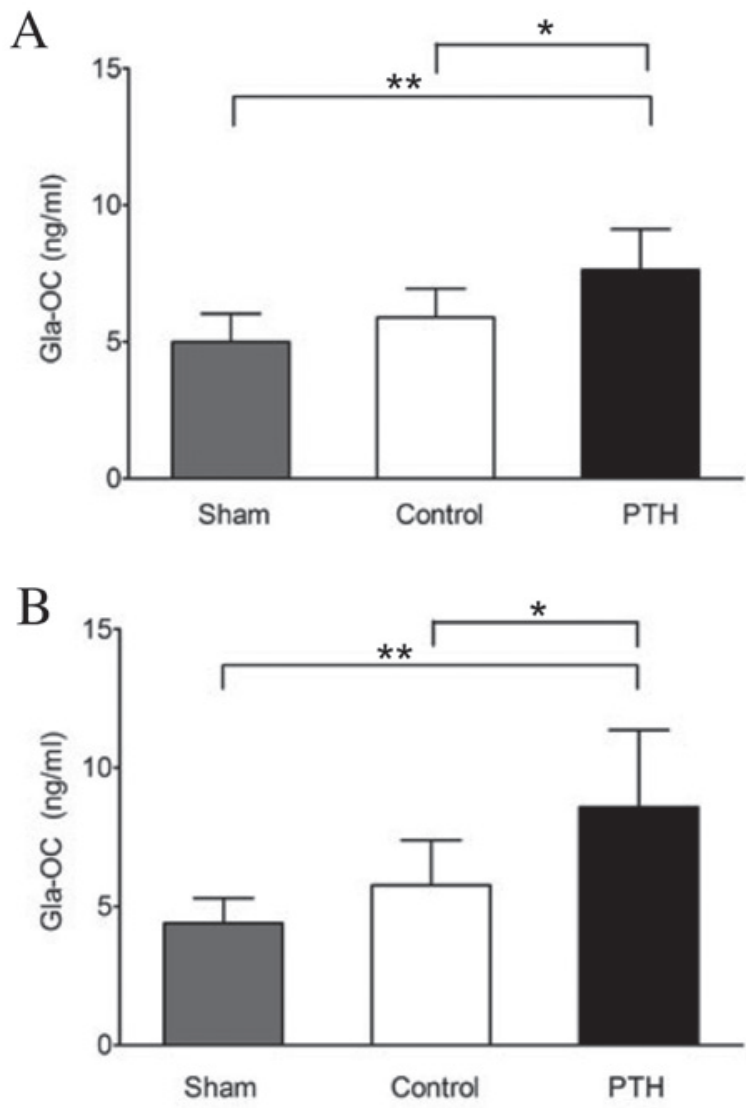

Figure 1. Serum levels of Gla-OC in rabbits administered teriparatide. Following the graft of a bone defect with $67 \% \beta$-TCP, teriparatide $(40 \mu \mathrm{g} / \mathrm{kg})$ or $0.2 \%$ rabbit serum albumin solution as a vehicle control was subcutaneously injected to rabbits three times per week in PTH and Control groups, respectively, for (A) 4 weeks and (B) 8 weeks. In the Sham group, a bone defect was created in the distal metaphysis and lateral condyle of the femur, but $\beta$-TCP granules were not grafted. These animals were subcutaneously injected with $0.2 \%$ rabbit serum albumin solution. Serum Gla-OC was subsequently measured. Data are expressed as mean \pm standard deviation $(\mathrm{n}=6) .{ }^{*} \mathrm{P}<0.05$ and ${ }^{* *} \mathrm{P}<0.01$. Gla-OC, $\gamma$-carboxylated osteocalcin; $\beta$-TCP, $\beta$-tricalcium phosphate; $\mathrm{PTH}$, parathyroid hormone.

multinucleated giant cell in contact with the surface of a bone or bone substitute, and N.Oc/BS and Oc.S/BS were calculated using TRAP-stained sections.

In the Control group, histomorphometry was performed using sections of distal femoral condyles without bone defect obtained from unoperated femurs.

Mechanical testing. The grafts were evaluated with an axial push-out load to failure test using MTS858 Mini Bionix2 (MTS Systems Corporation, Eden Prairie, MN, USA) and the appropriate software (MTS Test Star 790.00 version 4.00; MTS Systems Corporation). The specimens were placed on a metal piston jig with a diameter of $4.0 \mathrm{~mm}$, and continuous load-displacement data at a test speed of $0.5 \mathrm{~mm} / \mathrm{min}$ were recorded until the graft surface was depressed to a depth of $2.0 \mathrm{~mm}$. The maximum shear stiffness $(\mathrm{Mpa} / \mathrm{mm})$ was obtained from the slope of the linear section of the load-displacement curve, and the total energy absorption $\left(\mathrm{J} / \mathrm{m}^{2}\right)$ was calculated as the area under the load-displacement curve. Maximum shear strength $(\mathrm{MPa})$ was determined from the maximum force applied until failure of the bone and artificial bone (45). 
A
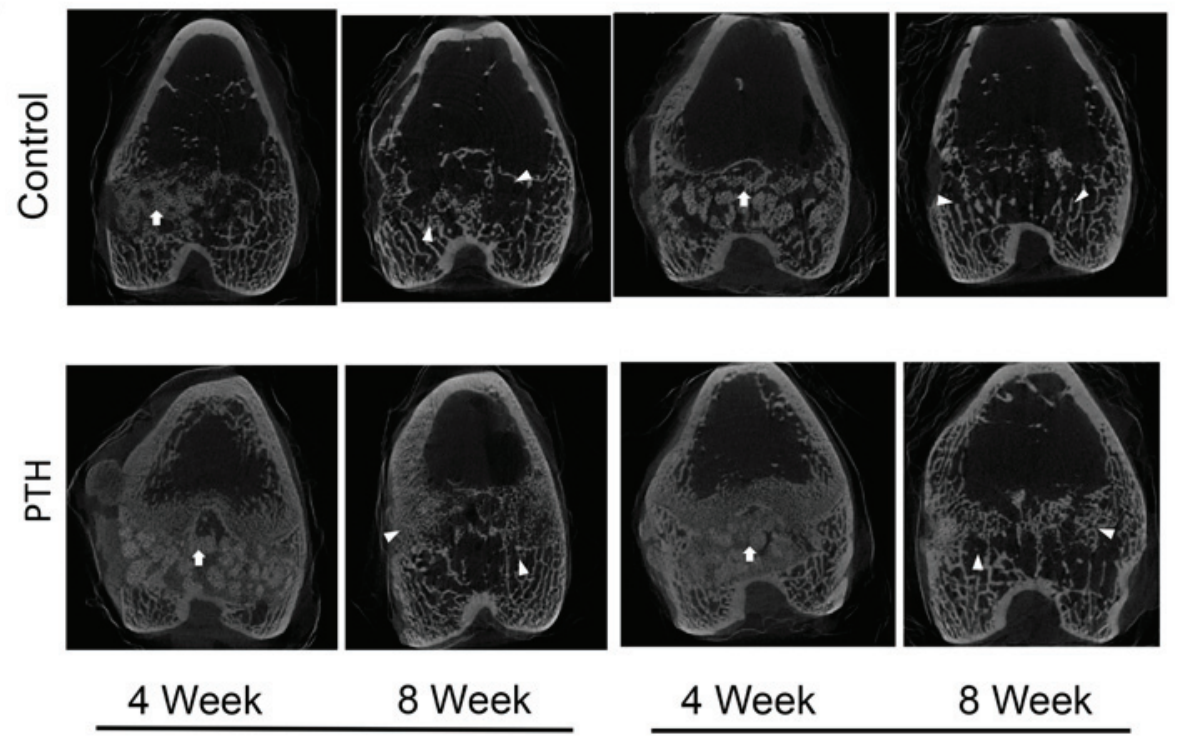

Porosity of $67 \%$

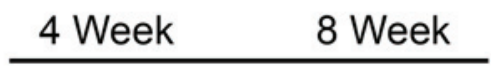

Porosity of $75 \%$

B

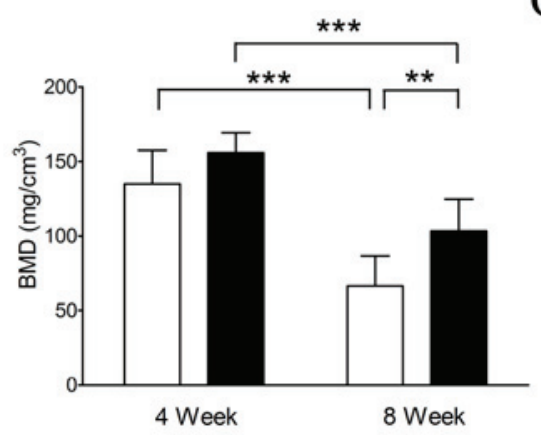

$\mathrm{C}$

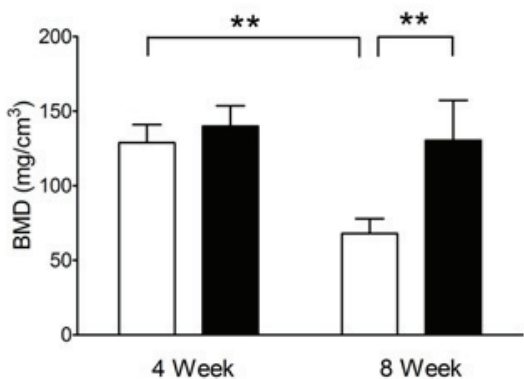

Figure 2. Radiological images and BMD of the $\beta$-TCP grafted sites of rabbit femurs analyzed with micro-CT. (A) Distal femoral condyles of the Control and PTH groups were recovered at 4 and 8 weeks following the graft with $\beta$-TCP with porosities of 67 and $75 \%$, and analyzed with micro-CT. Arrows and arrowheads indicate grafted $\beta$-TCP and the trabecular structure observed following the absorption of $\beta$-TCP, respectively. Images are representative of 6 rabbits from each group. BMD values at the femoral condyle graft sites were calculated from micro-CT images for $\beta$-TCP grafting with the porosity of (B) $67 \%$ and (C) $75 \%$ for the Control and PTH groups. Data are expressed as mean \pm standard deviation $(\mathrm{n}=6) .{ }^{* *} \mathrm{P}<0.01$ and ${ }^{* * * *} \mathrm{P}<0.001$. BMD, bone material density; $\beta$-TCP, $\beta$-tricalcium phosphate; $\mathrm{CT}$, computed tomography; $\mathrm{PTH}$, parathyroid hormone.

Statistical analysis. All data are expressed as the mean \pm standard deviation. Statistical analysis was performed using one-way analysis of variance followed by Bonferroni's multiple comparison test (GraphPad Prism; GraphPad Software, Inc., La Jolla, CA, USA). $\mathrm{P}<0.05$ was considered to indicate a statistically significant difference.

\section{Results}

Evaluation of bone metabolism using Gla-OC. Following grafting with $\beta$-TCP, teriparatide $(40 \mu \mathrm{g} / \mathrm{kg})$ or a vehicle was subcutaneously injected into rabbits for 4 or 8 weeks, and serum Gla-OC, which is a specific marker for bone formation, was subsequently measured. The Gla-OC levels were significantly higher in the PTH group than in the Sham $(\mathrm{P}<0.01)$ and Control groups $(\mathrm{P}<0.05)$ at both 4 and 8 weeks (Fig. 1). By contrast, no significant difference in Gla-OC levels was observed between the Control (with $\beta$-TCP graft) and Sham (without $\beta$-TCP graft) groups at 4 or 8 weeks. These observations suggest that increased levels of serum Gla-OC may be due to teriparatide-induced bone formation but not the $\beta$-TCP graft.

Radiological analysis \& measurement of BMD. Micro-CT analysis revealed that $\beta$-TCP was clearly present in the grafted bone in the Control group at 4 weeks following graft surgery; however, $\beta$-TCP was absorbed and the granular structure was markedly increased in the grafted bone around $\beta$-TCP granules in the PTH group for both porosities of $\beta$-TCP (Fig. 2A).

Furthermore, micro-CT analysis indicated that, at 8 weeks, $\beta$-TCP was mostly absorbed and replaced with trabecular structure, possibly cancellous bone, in the Control group (Fig. 2A), and the structure was notably increased in the grafted bones with both the porosity of 67 and $75 \%$ in the PTH group (Fig. 2A).

BMD was quantified based on the results of micro-CT analysis. The results indicated that BMD was significantly 
Control

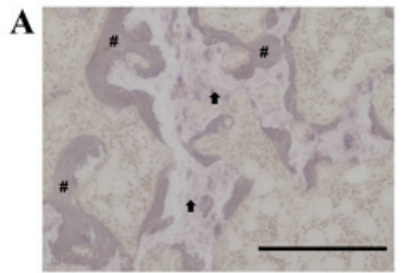

C
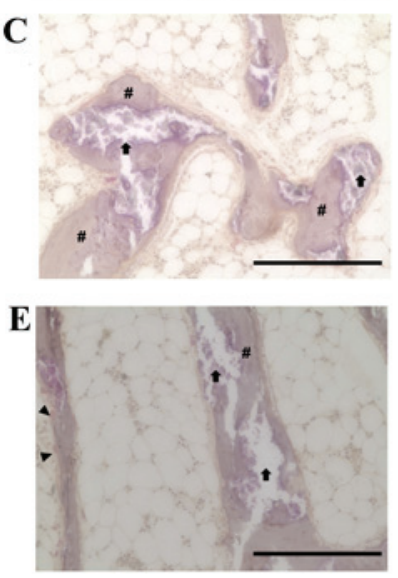

G

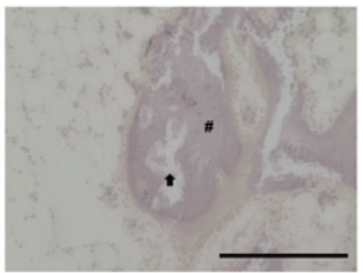

PTH

B

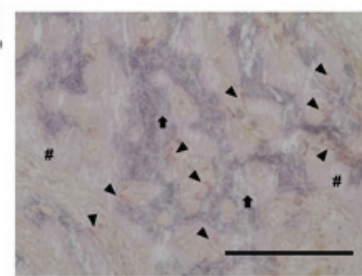

D

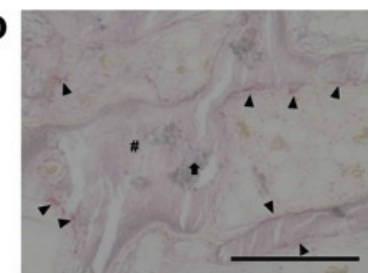

$\mathbf{F}$

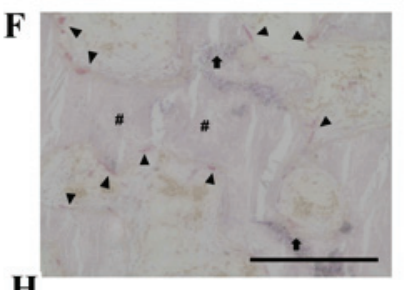

$\mathbf{H}$

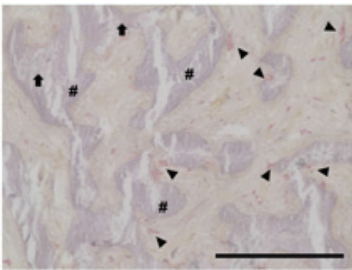

Figure 3. TRAP staining of the $\beta$-TCP grafted sites of rabbit femurs Distal femoral condyles of the (A) Control and (B) PTH groups at 4 weeks and (C) Control and (D) PTH groups at 8 weeks following application of the graft with $67 \%$ porosity. Distal femoral condyles of the (E) Control and (F) PTH groups at 4 weeks and $(\mathrm{G})$ Control and $(\mathrm{H})$ PTH groups at 8 weeks following application of the graft with $75 \%$ porosity. Sections were stained for TRAP-positive osteoclasts and counterstained with hematoxylin and nuclear fast red. Arrows, hash marks and arrowheads indicate grafted $\beta$-TCP, newly formed bone and TRAP-positive osteoclasts, respectively. Images are representative of 6 rabbits in each group. Scale bar, $300 \mu \mathrm{m}$ TRAP, tartrate resistant acid phosphatase; $\beta$-TCP, $\beta$-tricalcium phosphate; PTH, parathyroid hormone.

decreased ( $\sim 50 \%)$ between 4 and 8 weeks following the graft with the porosity of $67(\mathrm{P}<0.001)$ and $75 \%(\mathrm{P}<0.01$; Fig $2 \mathrm{~B})$ in the Control group. By contrast, BMD was only decreased by $\sim 30 \%$ in the PTH group following the graft with $67 \%$ porosity, although this reduction was significant $(\mathrm{P}<0.001$; Fig. $2 \mathrm{~B})$. The reduction in BMD was almost completely suppressed in the PTH group following the graft with $75 \%$ porosity, with no significant differences in BMD observed between weeks 4 and 8 (Fig. 2C). Notably, BMD was significantly increased in the PTH group compared with the Control group at 8 weeks post-graft for both 67 and $75 \%$ porosity $(\mathrm{P}<0.01$; Fig. 2B and C). These observations suggest that teriparatide administration enhances calcification in bone defects grafted with $\beta$-TCP of 67 and $75 \%$ porosity.

Histological analysis. Histological analysis revealed that the number of TRAP-positive osteoclasts was markedly increased in the PTH group compared with the Control group for bone

Control

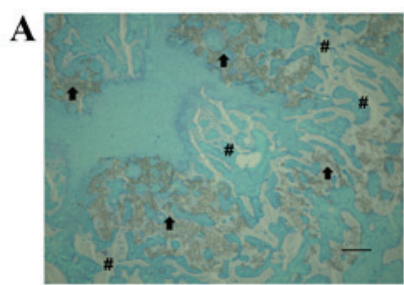

C
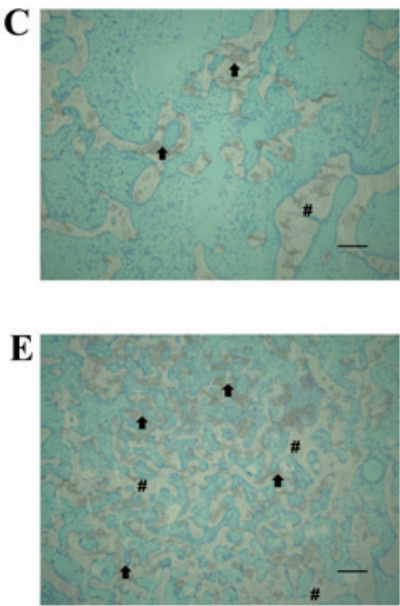

G

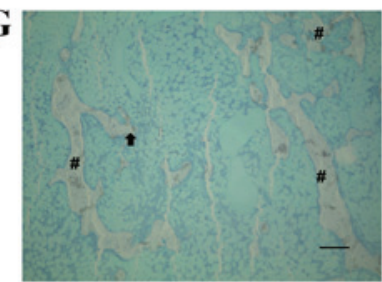

PTH
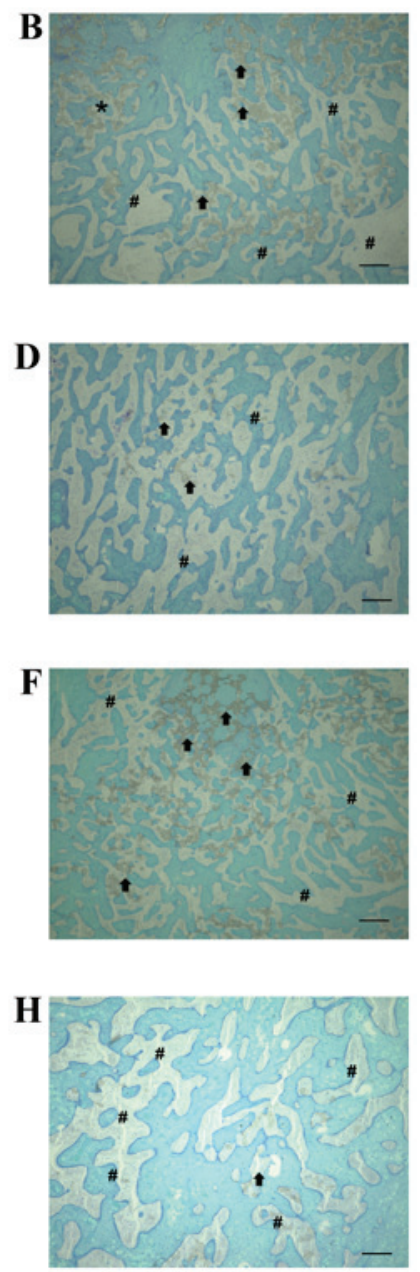

Figure 4. Giemsa staining of the $\beta$-TCP grafted sites of the rabbit femur. Distal femoral condyles of the (A) Control and (B) PTH groups at 4 weeks and (C) Control and (D) PTH groups at 8 weeks following the graft with $67 \%$ porosity. Distal femoral condyles of the (E) Control and (F) PTH groups at 4 weeks and $(\mathrm{G})$ Control and (H) PTH groups at 8 weeks following the graft with $75 \%$ porosity. Arrows and hash marks indicate the grafted $\beta$-TCP and newly formed bone, respectively. Images are representative of 6 rabbits in each group. Scale bar, $300 \mu \mathrm{m}$. $\beta$-TCP, $\beta$-tricalcium phosphate; PTH, parathyroid hormone.

grafted with $\beta$-TCP at porosities of 67 and $75 \%$ (Fig. 3). TRAP-positive osteoclasts were in direct contact with the surface of newly formed bone as well as $\beta$-TCP, with a ragged appearance of these structures. Furthermore, the amount of $\beta$-TCP at porosities of 67 and $75 \%$ was markedly decreased at 8 weeks compared with 4 weeks in both the Control and PTH groups (Fig. 4). Notably, the amount of newly formed bone was increased in the PTH group compared with the Control group at 4 and 8 weeks following the graft for both porosities of $\beta$-TCP (Fig. 4).

Histomorphometry. Histomorphometric analysis was first performed using sections of distal femoral condyles without bone defects, obtained from unoperated femurs. The results demonstrated a significant increase in $\mathrm{BV} / \mathrm{TV}(\mathrm{P}<0.05)$ and BFR/BS $(\mathrm{P}<0.01)$ at 4 weeks (Fig. 5A and $\mathrm{B})$, and significant increases in BV/TV, MAR and BFR/BV at 8 weeks $(\mathrm{P}<0.01$; Fig. 5A-C) in the PTH group compared with the Control 

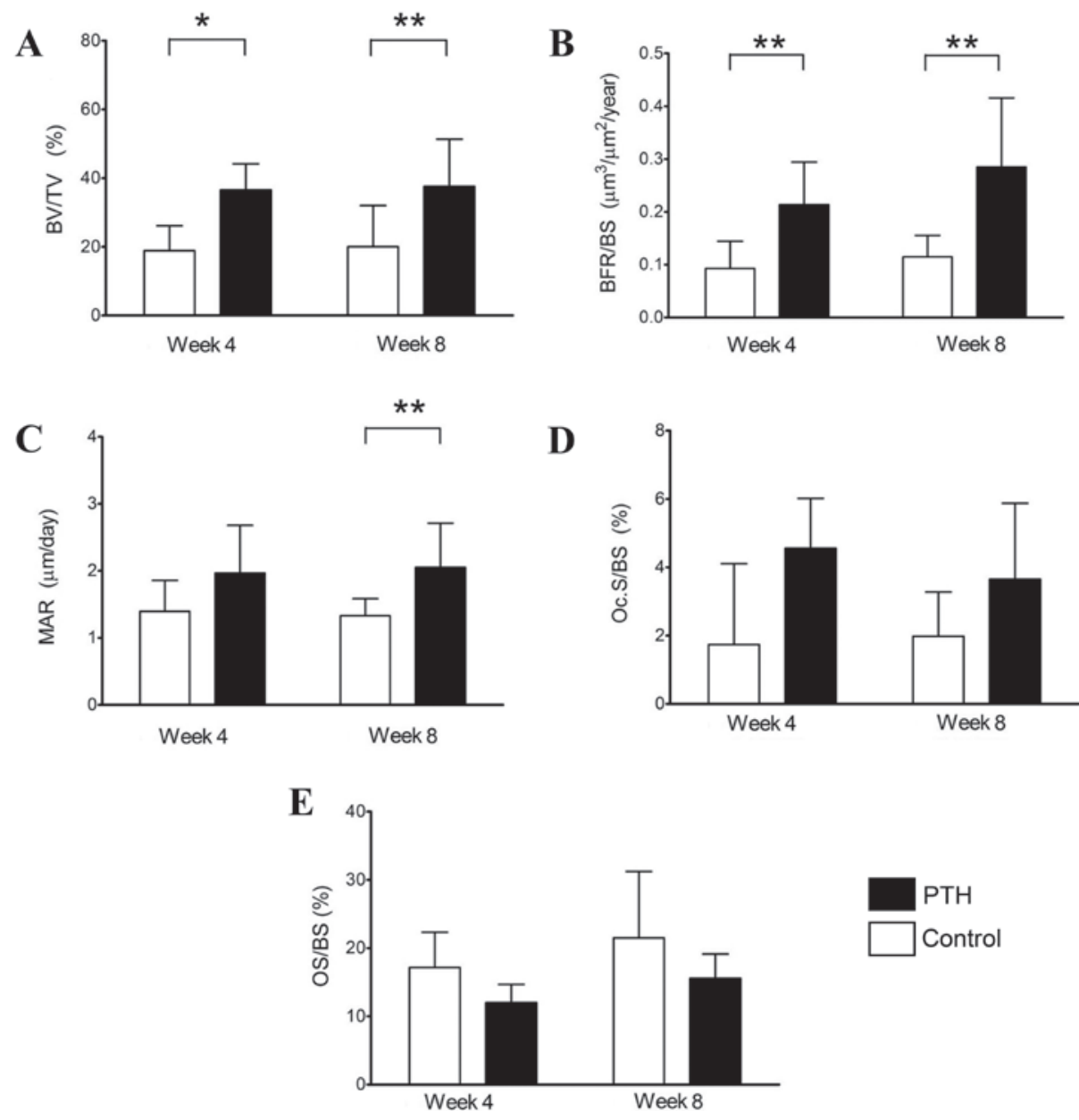

Figure 5. Histomorphometry of the distal femoral condyles without bone defects. Histomorphometric analyses were performed using sections of the distal femoral condyles of the Control and PTH groups, which were recovered at 4 and 8 weeks post-surgery. (A) BV/TV, (B) BFR/BS, (C) MAR, (D) Oc.S/BS and (E) OS/BS were determined. Data are expressed as mean \pm standard deviation $(\mathrm{n}=6)$. ${ }^{*} \mathrm{P}<0.05$ and ${ }^{* *} \mathrm{P}<0.01$. PTH, parathyroid hormone; BV bone volume; TV, tissue volume; BFR, bone formation rate; BS, bone surface; MAR, mineral apposition rate/calcification; Oc.S, osteoclast surface; OS, osteoid surface.

group (without teriparatide). These observations suggest that teriparatide administration enhances the BV, MAR and BFR in distal femoral condyles without bone defect. No significant differences were observed in Oc.S/BS or OS/BS between the Control and PTH groups at weeks 4 or 8 (Fig. 5D and E).

Furthermore, histomorphometric analysis was performed using sections of distal femoral condyles with bone defects and $\beta$-TCP grafts (Figs. 6 and 7). The volume of $\beta$-TCP (TCPV/TV) was decreased between weeks 4 and 8 in both the Control and PTH groups following grafts with 67 and $75 \%$ porosity (Figs. 6A and 7A, respectively). By contrast, the volume of newly formed bone, (BV- TCPV)/TV, was significantly increased between weeks 4 to 8 in the PTH groups with grafts of both porosities $(\mathrm{P}<0.05$; Figs. $6 \mathrm{~B}$ and $7 \mathrm{~B})$. Additionally, the volume of newly formed bone was significantly increased in the PTH group compared with the Control group grafted with $67 \% \beta$-TCP at 4 weeks $(\mathrm{P}<0.05$; Fig. $6 \mathrm{~B})$.

The calcification rate (MAR) was significantly higher in the PTH group compared with the Control group at 4 and 8 weeks following grafting with both porosities of $\beta$-TCP $(\mathrm{P}<0.05$ for $67 \%, \mathrm{P}<0.01$ for $75 \%$; Figs. $6 \mathrm{C}$ and $7 \mathrm{C}$, respectively). Calcification was indicated to be increased in the PTH group compared with the Control group at 4 and 8 weeks following grafting with both porosities of 67 and
$75 \% \beta$-TCP by labeling with a calcium-binding fluorescent dye calcein (Fig. 8). BFR/BS was significantly increased in the PTH group compared with the Control group at 4 weeks for both porosities of $\beta$-TCP $(\mathrm{P}<0.05)$; however, no significant differences were observed at 8 weeks after bone grafting (Figs. 6D and 7D).

N.Oc/BS and Oc.S/BS were significantly increased in the PTH group compared with the Control group for both porosities of $\beta$-TCP at 4 weeks $(\mathrm{P}<0.05)$ and 8 weeks $(\mathrm{P}<0.01)$ following the bone graft (Fig. 6E and F, and Fig. 7E and F). Furthermore, OS/BS significantly increased in the Control group from week 4 to week 8 for the two porosities of $\beta$-TCP $(\mathrm{P}<0.05)$; however, OS/BS was significantly lower in the PTH group compared with the Control group with $\beta$-TCP porosities of $67(\mathrm{P}<0.01)$ and $75 \%(\mathrm{P}<0.001)$ at 8 weeks following the bone graft (Figs. 6G and 7G). This reduction in OS in the PTH group may be due to the action of teriparatide, which substantially enhances the bone formation, thereby decreasing OS/BS.

Mechanical strength analysis. Maximum shear strength of the bone grafts was significantly increased in the PTH groups compared with the Control groups at 4 weeks for $\beta$-TCP grafts of $67 \%$ porosity $(\mathrm{P}<0.05$; Fig. $9 \mathrm{~A})$ and at 8 weeks for $\beta$-TCP grafts of both porosities $(\mathrm{P}<0.05$ for $67 \%, \mathrm{P}<0.01$ for 

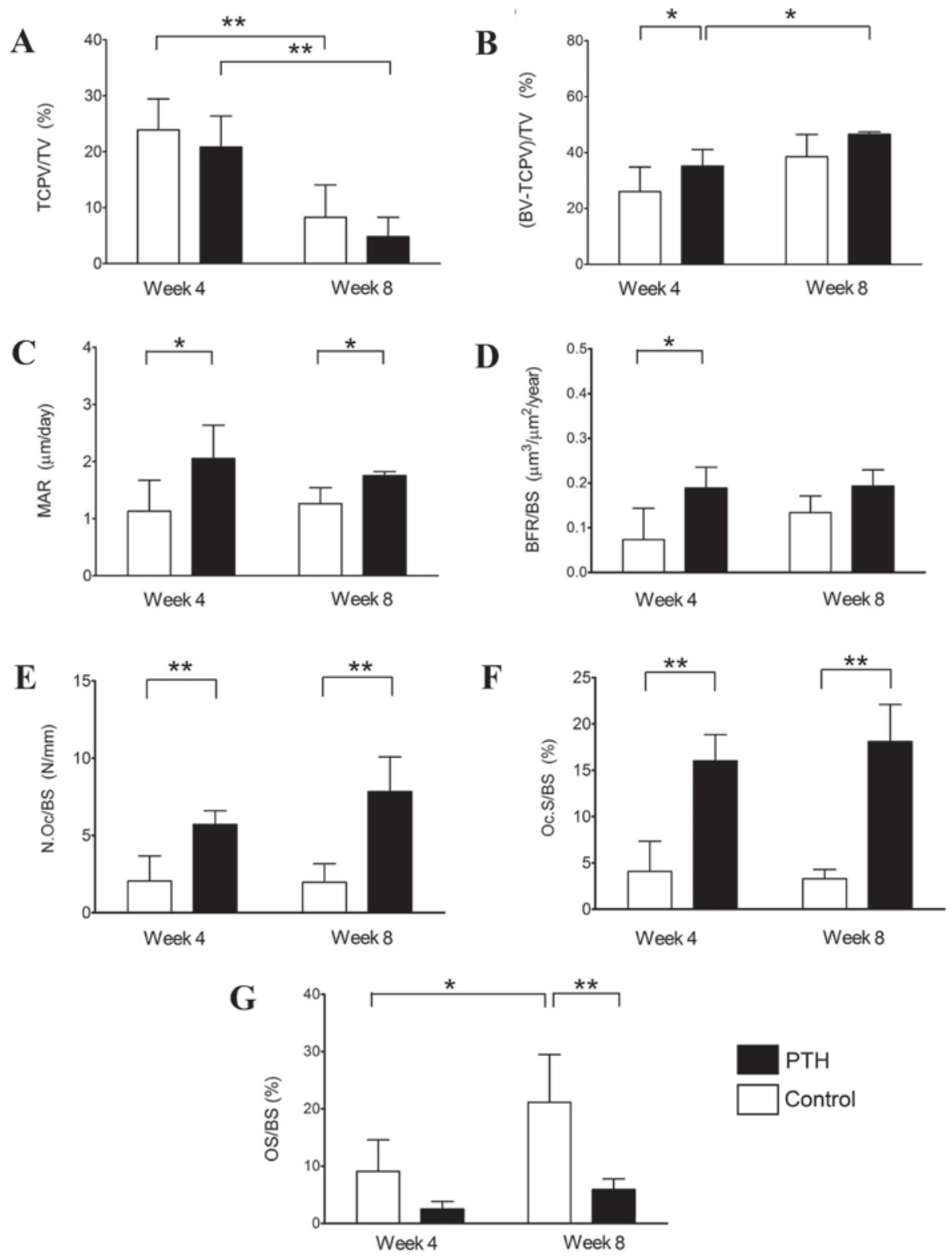

Figure 6. Histomorphometry of bone defects grafted with $\beta-\mathrm{TCP}$ of $67 \%$ porosity. Histomorphometric analyses were performed using sections of distal femoral condylesof the ControlandPTHgroups, which were recoveredat4and8 weekspost-surgery, and(A)TCP/TV,(B)BV-TCPV/TV,(C)MAR,(D)BFR/BS,(E)N.Oc/BS, (F) Oc.S/BS and (G) OS/BS were determined. Data are expressed as mean \pm standard deviation $(\mathrm{n}=6)$. ${ }^{*} \mathrm{P}<0.05$ and ${ }^{* *} \mathrm{P}<0.01$. TCP, tricalcium phosphate; $\mathrm{PTH}$, parathyroid hormone; TV, tissue volume; BV, bone volume; TCPV, TCP volume; BV-TCPV/TV, newly formed bone; MAR, mineral apposition rate/calcification; BFR, bone formation rate; BS, bone surface; N.Oc, osteoclast number; Oc.S, osteoclast surface; OS, osteoid surface.

75\%; Fig. 9A and B). Notably, the maximum shear strength was significantly decreased between 4 and 8 weeks in the Control groups at both porosities of $\beta$-TCP $(\mathrm{P}<0.001$; Fig. 9A and $\mathrm{B}$ ); however, the maximum shear strength was maintained by teriparatide administration to almost the same levels at 8 weeks as those of the Control groups at 4 weeks for both porosities of $\beta$-TCP (Fig. 9A and B).

A significant increase in maximum shear stiffness was observed in the PTH group compared with the control at 4 $(\mathrm{P}<0.05)$ and $8(\mathrm{P}<0.01)$ weeks following the application of bone grafts with $67 \%$ porosity $\beta$-TCP (Fig. 9C); however, no significant difference in this parameter was observed between groups for the $75 \%$ porosity graft (Fig. 9D). Significant increases in total energy absorption were also observed in the PTH group compared with the control for the $67 \%$ porosity graft $(\mathrm{P}<0.001$ at week 4 and $\mathrm{P}<0.05$ at week 8; Fig. 9E), but not for the graft using 75\% $\beta$-TCP (Fig. 9F).

\section{Discussion}

Grafting $\beta$-TCP is a well-established method for restoring bone defects; however, there is a concern that the mechanical stability of grafted $\beta$-TCP is not maintained during bone translation (23). Notably, the intermittent administration of teriparatide (hPTH 1-34) reduces the risk of fracture in patients with osteoporosis and works as an anabolic agent to stimulate bone formation (46). In the present study, therefore, the effect of intermittent administration of teriparatide on new bone formation and mechanical strength of bone defects grafted with $\beta$-TCP was investigated. The results indicated that 

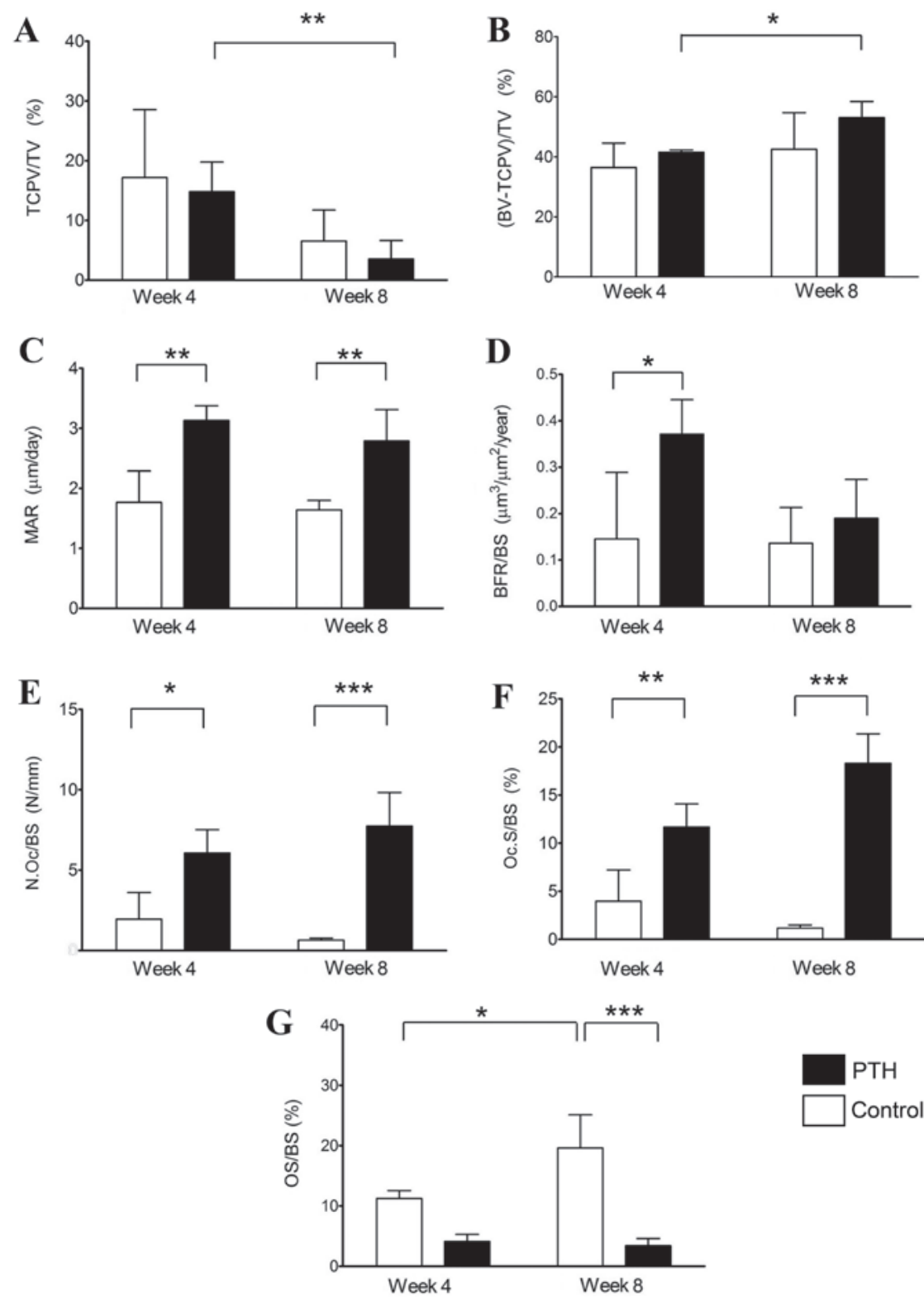

Figure 7. Histomorphometry of the bone defect grafted with $\beta$-TCP of $75 \%$ porosity. Histomorphometric analyses were performed using sections of distal femoral condyles of the Control and PTH groups, which were recovered at 4 and 8 weeks post-surgery, and (A) TCP/TV, (B) BV-TCPV/TV, (C) MAR, (D) BFR/BS, (E) N.Oc/BS, (F) Oc.S/BS and (G) OS/BS were determined. Data are expressed as mean \pm standard deviation $(\mathrm{n}=6)$. " $\mathrm{P}<0.05$ and ${ }^{* *} \mathrm{P}<0.01$. TCP, tricalcium phosphate; PTH, parathyroid hormone; TV, tissue volume; BV, bone volume; TCPV, TCP volume; BV-TCPV/TV, newly formed bone; MAR, mineral apposition rate/calcification; BFR, bone formation rate; BS, bone surface; N.Oc, osteoclast number; Oc.S, osteoclast surface; OS, osteoid surface.

intermittent teriparatide administration suppressed the reduction in mechanical strength during the remodeling process in bone defects grafted with $\beta$-TCP. Furthermore, the results of the present study indicate that teriparatide increases the degradation of $\beta$-TCP by osteoclastic resorption and promotes the formation of new bone following grafting. These observations demonstrate that teriparatide is effective at maintaining the mechanical stability of grafted $\beta$-TCP, possibly by promoting new bone formation.

The experimental model used in the present study was designed to evaluate the effect of intermittent administration of teriparatide on the regeneration of cancellous bone defects grafted with $\beta$-TCP. White Japanese rabbits were chosen as a testing model due to the ease of handling and the anatomical characteristics of their femurs $(47,48)$, and bone metabolism closely resembling that in humans (49-53). Previous studies have indicated that the femoral condyle may be used as a site for evaluating the mechanical strength and bone formation in defects grafted with bone substitutes (47,48,54-56). In the present study, the radiological, histological and mechanical strength analyses of defected bone were performed at 4 and 8 weeks following $\beta$-TCP graft; these intervals were selected because a period of 6 weeks is required for bone formation in rabbits (27,57-59), and teriparatide accelerates the bone remodeling process 4 weeks following intermittent administration $(31,60,61)$.

The anabolic effect of teriparatide is dependent on the dose, frequency and duration of administration (62-64). In previous studies, 6-10 $\mu \mathrm{g} / \mathrm{kg}$ teriparatide was subcutaneously injected into rats and rabbits three times per week (62-64). In the 

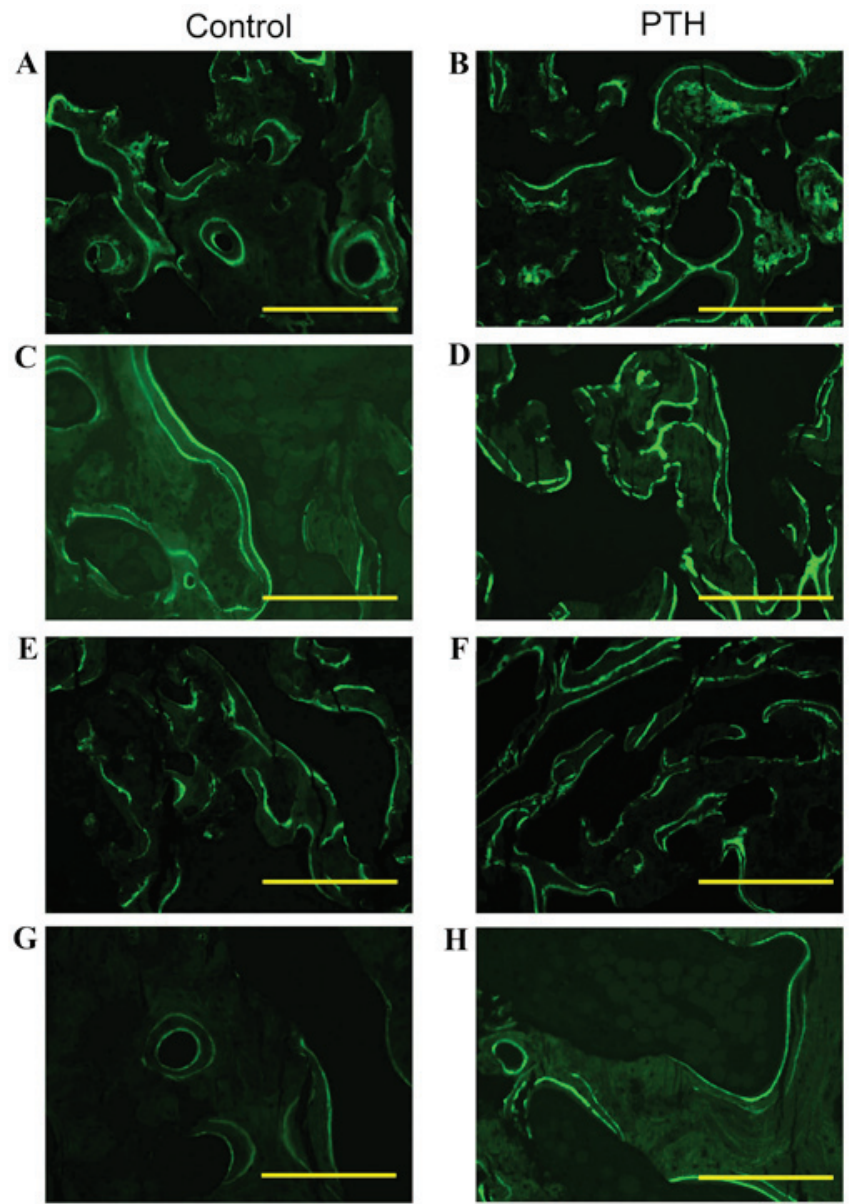

Figure 8. Evaluation of bone formation and remodeling in bone defects grafted with $\beta$-TCP using fluorescent labeling. Calcein, a calcium-binding fluorescent dye was used to evaluate bone formation and remodeling in bone defects grafted with $67 \%$ porosity $\beta$-TCP in the (A) Control and (B) PTH groups at 4 weeks, and in the (C) Control and (D) PTH groups at 8 weeks. Bone formation and remodeling in bone defects grafted with $75 \%$ porosity $\beta$-TCP in the (E) Control group and (F) PTH groups at 4 weeks and in the (G) Control and (H) PTH groups at 8 weeks. Images are representative of 6 rabbits in each group. Scale bar, $300 \mu \mathrm{m}$. $\beta$-TCP, $\beta$-tricalcium phosphate; $\mathrm{PTH}$, parathyroid hormone.

present study, to make the effect of teriparatide more evident, $40 \mu \mathrm{g} / \mathrm{kg}$ teriparatide was subcutaneously injected three times per week, and it was confirmed that teriparatide significantly increased the serum levels of Gla-OC at 4 and 8 weeks. Furthermore, teriparatide significantly increased the calcification, bone formation and newly formed bone following the graft compared with that in the Control group. These results indicate that teriparatide enhances bone formation in bone defects grafted with $\beta$-TCP. Micro-CT analysis also revealed that the reduction in BMD during the experimental period was suppressed, and BMD was maintained during the experimental period in the teriparatide-treated group following the graft.

In the Control group, TCPV was significantly decreased between weeks 4 and 8 , whereas the volume of newly formed bone was increased. However, maximum shear strength significantly decreased between weeks 4 and 8 in the Control group. These results suggest that the bioresorption of $\beta$-TCP causes the mechanical loss of bone grafted with $\beta$-TCP, although the volume of newly formed bone increases, as previously reported $(21,23,65)$. Notably, teriparatide further decreased the volume of $\beta$-TCP and increased the volume of newly formed bone between weeks 4 and 8 compared with the Control group at both porosities of $\beta$-TCP. These results suggest that teriparatide increases both the biodegradation of $\beta$-TCP and new bone formation in bone defects grafted with $\beta$-TCP. In this context, it is interesting to note that based on the activity of teriparatide (inducing osteoclast differentiation and activation), bone resorption is transiently increased at an early stage following teriparatide administration; however, bone formation is significantly increased at a late phase following the administration (66). Importantly, teriparatide administration increased all mechanical parameters (maximum shear strength, maximum shear stiffness and total energy absorption) at 4 and 8 weeks compared with the Control group, when $\beta$-TCP with $67 \%$ porosity was used. By contrast, only maximum shear strength was increased by teriparatide at 8 weeks when using the porosity of $75 \%$. These results suggest that $\beta$-TCP of 67 but not $75 \%$ porosity may be useful as a bone substitute, which enhances the remodeling and mechanical strength of bone defects, potentially by promoting the resorption of $\beta$-TCP and new bone formation.

It has been reported that during the bone remodeling process in $\beta$-TCP grafted sites, osteoclasts continuously adhere to the surface of $\beta$-TCP and resorb the material, and their biodegradation stimulates bone formation (67-70). Furthermore, a previous study indicated that the number of osteoclasts peaks early, whereas the rate of new bone formation peaks later in bone defects grafted with $\beta$-TCP (27). Based on these observations, it may be speculated that the bioresorption of $\beta$-TCP by osteoclasts is responsible for the reduction in mechanical strength of bone grafted with $\beta$-TCP until new bone formation is completed. Consistent with this, the maximum shear strength was reduced between weeks 4 and 8 in the Control group. Notably, the maximum shear strength was maintained by teriparatide administration, possibly via the increase in calcification or new bone formation.

In conclusion, the results of the present study revealed that intermittent administration of teriparatide enhances the remodeling of bone defects grafted with $\beta$-TCP. Teriparatide likely increases the degradation of $\beta$-TCP by osteoclastic resorption and promotes the formation of new bone following grafting, thereby suppressing the reduction in mechanical strength during the remodeling process of bone defects grafted with $\beta$-TCP. Thus, the combination of an anabolic agent (e.g., teriparatide) and a bone graft substitute (e.g., $\beta$-TCP) may have useful clinical applications in spinal fusion surgery and augmentation in revision arthroplasty.

\section{Acknowledgements}

The authors would like to thank Associate Professor Kiyohito Naito (Department of Medicine for Motor Organs, Juntendo University Graduate School of Medicine, Tokyo, Japan) for helpful discussion, Masahiro Miyazaki (Department of Bio-Engineering, Juntendo University Institute of Casualty Center, Shizuoka, Japan) and the members of the Laboratory of Division of Molecular \& Biochemical Research, Research Support Center, Juntendo University Graduate Faculty of Medicine (Tokyo, Japan), for technical assistance. The authors would also like to thank Asahi Kasei Pharma Corp. 

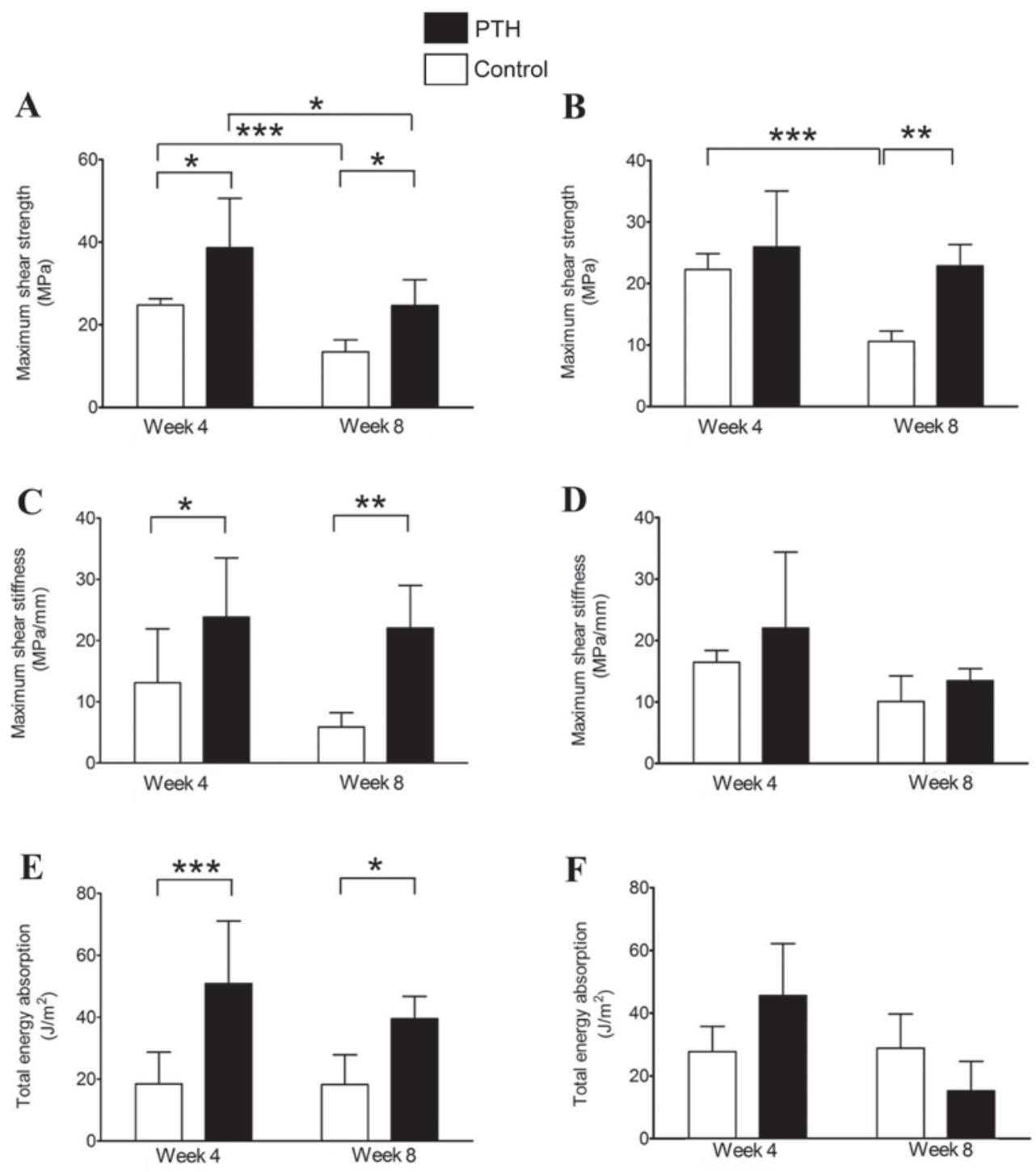

Figure 9. Mechanical strength analysis of the bone defect site. Mechanical strength analyses were performed using the graft sites of distal femoral condyles of the Control and PTH groups, which were recovered at 4 and 8 weeks following grafting with $\beta$-TCP of 67 or $75 \%$ porosity. Maximum shear strength for (A) 67 and (B) $75 \%$ porosity of $\beta$-TCP. Maximum shear stiffness for (C) 67 and (D) $75 \%$ porosity of $\beta$-TCP. Total energy absorption for (E) 67 and (F) $75 \%$ porosity of $\beta$-TCP. Data are expressed as the mean \pm standard deviation of 6 rabbits in each group. ${ }^{*} \mathrm{P}<0.05,{ }^{* *} \mathrm{P}<0.01$ and ${ }^{* * * *} \mathrm{P}<0.001$. PTH, parathyroid hormone; $\beta$-TCP, $\beta$-tricalcium phosphate.

and HOYA Corporation for their supplies of teriparatide and $\beta$-TCP, respectively. This study was supported in part by a grant from the Strategic Research Foundation Grant-aided Project for Private Universities from Ministry of Education, Culture, Sport, Science, and Technology, Japan, 2014-2018 (grant no. S1411007).

\section{References}

1. Weinstein JN, Lurie JD, Olson PR, Bronner KK and Fisher ES United States trends and regional variations in lumbar spine surgery: 1992-2003. Spine (Phila Pa 1976) 31: 2707-2714, 2007.

2. Chau AM and Mobbs RJ: Bone graft substitutes in anterior cervical discectomy and fusion. Eur Spine J 18: 449-464, 2009.

3. Bicanic G, Barbaric K, Bohacek I, Aljinovic A and Delimar D: Current concept in dysplastic hip arthroplasty: Techniques for acetabular and femoral reconstruction. World J Orthop 5: 412-424, 2014

4. Lee JM and Nam HT: Acetabular revision total hip arthroplasty using an impacted morselized allograft and a cementless cup Minimum 10-year follow-up. J Arthroplasty 26: 1057-1060, 2011.
5. Dewei Z and Xiaobing Y: A retrospective analysis of the use of cannulated compression screws and a vascularised iliac bone graft in the treatment of displaced fracture of the femoral neck in patients aged $<50$ years. Bone Joint J 96-B: 1024-1028, 2014.

6. Herkowitz HN and Kurz LT: Degenerative lumbar spondylolisthesis with spinal stenosis. A prospective study comparing decompression with decompression and intertransverse process arthrodesis. J Bone Joint Surg Am 73: 802-808, 1991.

7. Zdeblick TA: A prospective, randomized study of lumbar fusion. Preliminary results. Spine (Phila Pa 1976) 18: 983-991, 1993.

8. Iwasaki K, Ikedo T, Hashikata $\mathrm{H}$ and Toda H: Autologous clavicle bone graft for anterior cervical discectomy and fusion with titanium interbody cage. J Neurosurg Spine 21: 761-768, 2014.

9. Summers BN and Eisenstein SM: Donor site pain from the ilium. A complication of lumbar spine fusion. J Bone Joint Surg Br 71: 677-680, 1989.

10. Aurori BF, Weierman RJ, Lowell HA, Nadel CI and Parsons JR: Pseudoarthrosis after spinal fusion for scoliosis. A comparison of autogenic and allogenic bone grafts. Clin Orthop Relat Res 153-158, 1985.

11. Park JJ, Hershman SH and Kim YH: Updates in the use of bone grafts in the lumbar spine. Bull Hosp Jt Dis 71: 39-48, 2013.

12. Giannoudis PV, Dinopoulos H and Tsiridis E: Bone substitutes: An update. Injury 36 (Suppl 3): S20-S27, 2005. 
13. Myoui $\mathrm{A}$ and Yoshikawa $\mathrm{H}$ : Regenerative medicine in bone tumor surgery. Clin Calcium 18: 1767-1773, 2008 (In Japanese).

14. Tamai N, Myoui A, Tomita T, Nakase T, Tanaka J, Ochi T and Yoshikawa H: Novel hydroxyapatite ceramics with an interconnective porous structure exhibit superior osteoconduction in vivo. J Biomed Mater Res 59: 110-117, 2002.

15. Matsumine A, Myoui A, Kusuzaki K, Araki N, Seto M, Yoshikawa $\mathrm{H}$ and Uchida A: Calcium hydroxyapatite ceramic implants in bone tumor surgery. A long-term follow-up study. J Bone Joint Surg Br 86: 719-725, 2004.

16. Hoogendoorn HA, Renooij W, Akkermans LM, Visser W and Wittebol P: Long-term study of large ceramic implants (porous hydroxyapatite) in dog femora. Clin Orthop Relat Res 281-288, 1984.

17. Ozawa M: Experimental study on bone conductivity and absorbability of the pure $\beta$-TCP. J Jpn Soc Biomater 13: 167-175, 1995 (In Japanese).

18. Ozawa M, Tanaka T, Morikawa S, Chazono M and Fujii K Clinical study of the pure $\beta$-tricalcium phosphate-Reports of 167 cases. J East Jpn Orthop Traumatol 12: 409-413, 2000 (In Japanese).

19. Saito M, Shimizu H, Beppu M and Takagi M: The role of beta-tricalcium phosphate in vascularized periosteum. J Orthop Sci 5: 275-282, 2000.

20. Tanaka T, Chazono M and Komaki H: Clinical application of beta-tricalcium phosphate in human bone defects. Jikeikai Med J 53: 55-53, 2006.

21. Tanaka T, Kumagae Y, Saito M, Chazono M, Komaki H, Kikuchi T, Kitasato S and Marumo K: Bone Formation and Resorption in Patients After Implantation of beta-Tricalcium Phosphate blocks with $60 \%$ and $75 \%$ Porosity in Opening-Wedge High Tibial Osteotomy. J Biomed Mater Res B Appl Biomater 86: 453-459, 2007.

22. Dong J, Uemura T, Shirasaki Y and Tateishi T: Promotion of bone formation using highly pure porous beta-TCP combined with bone marrow-derived osteogenitor cells. Biomaterials 23 : 4493-4502, 2002.

23. Yamasaki N, Hirao M, Nanno K, Sugiyasu K, Tamai N, Hashimoto N, Yoshikawa $\mathrm{H}$ and Myoui A: A comparative assessment of synthetic ceramic bone substitutes with different composition and microstructure in rabbit femoral condyle model J Biomed Mater Res B Appl Biomater 91: 788-798, 2009.

24. Ng AM, Tan KK, Phang MY, Aziyati O, Tan GH, Isa MR, Aminuddin BS, Naseem M, Fauziah O and Ruszymah BH: Differential osteogenic activity of osteoprogenitor cells on HA and TCP/HA scaffold of tissue engineered bone. J Biomed Mater Res A 85: 301-312, 2007

25. Kitsugi T, Yamamoto T, Nakamura T, Kotani S, Kokubo T and Takeuchi H: Four calcium phosphate ceramics as bone substitutes for non-weight-bearing. Biomaterials 14: 216-224, 1993.

26. Finkemeier CG: Bone-grafting and bone-graft substitutes J Bone Joint Surg Am 84-A: 454-464, 2002.

27. Chazono M, Tanaka T, Komaki H and Fujii K: Bone formation and bioresorption after implantation of injectable beta-tricalcium phosphate granules-hyaluronate complex in rabbit bone defects. J Biomed Mater Res A 70: 542-549, 2004.

28. Yokoyama K, Matsuba D, Adachi-Akahane S, Takeyama $H$ Tabei I, Suzuki A, Shibasaki T, Iida R, Ohkido I, Hosoya T and Suda N: Dihydropyridine- and voltage-sensitive $\mathrm{Ca} 2+$ entry in human parathyroid cells. Exp Physiol 94: 847-855, 2009.

29. Black DM and Schafer AL: The search for the optimal anabolic osteoporosis therapy. J Bone Miner Res 28: 2263-2265, 2013.

30. Nakamura T, Sugimoto T, Nakano T, Kishimoto H, Ito M, Fukunaga M, Hagino H, Sone T, Yoshikawa H, Nishizawa Y, et al: Randomized teriparatide [human parathyroid hormone (PTH) 1-34] once-weekly efficacy research (TOWER) trial for examining the reduction in new vertebral fractures in subjects with primary osteoporosis and high fracture risk. J Clin Endocrinol Metab 97: 3097-3106, 2012

31. Hock JM and Gera I: Effects of continuous and intermittent administration and inhibition of resorption on the anabolic response of bone to parathyroid hormone. J Bone Miner Res 7: 65-72, 1992.

32. Hodsman AB, Bauer DC, Dempster DW, Dian L, Hanley DA, Harris ST, Kendler DL, McClung MR, Miller PD, Olszynski WP, et al: Parathyroid hormone and teriparatide for the treatment of osteoporosis: A review of the evidence and suggested guidelines for its use. Endocr Rev 26: 688-703, 2005.

33. Andreassen TT, Ejersted $\mathrm{C}$ and Oxlund $\mathrm{H}$ : Intermittent parathyroid hormone (1-34) treatment increases callus formation and mechanical strength of healing rat fractures. J Bone Miner Res 14: 960-968, 1999 .
34. Andreassen TT, Fledelius C, Ejersted C and Oxlund H: Increases in callus formation and mechanical strength of healing fractures in old rats treated with parathyroid hormone. Acta Orthop Scand 72: 304-307, 2001

35. Knopp E, Troiano N, Bouxsein M, Sun BH, Lostritto K, Gundberg C, Dziura J and Insogna K: The effect of aging on the skeletal response to intermittent treatment with parathyroid hormone. Endocrinology 146: 1983-1990, 2005.

36. Aleksyniene R, Thomsen JS, Eckardt H, Bundgaard KG, Lind M and Hvid I: Parathyroid hormone PTH(1-34) increases the volume, mineral content and mechanical properties of regenerated mineralizing tissue after distraction osteogenesis in rabbits. Acta Orthop 80: 716-723, 2009.

37. Mashiba T, Burr DB, Turner CH, Sato M, Cain RL and Hock JM: Effects of human parathyroid hormone (1-34), LY333334, on bone mass, remodeling, and mechanical properties of cortical bone during the first remodeling cycle in rabbits. Bone 28: 538-547, 2001.

38. Kaback LA, Soung do Y, Naik A, Geneau G, Schwarz EM, Rosier RN, O'Keefe RJ and Drissi H: Teriparatide (1-34 human PTH) regulation of osterix during fracture repair. J Cell Biochem 105: 219-226, 2008.

39. Glover SJ, Eastell R, McCloskey EV, Rogers A, Garnero P, Lowery J, Belleli R, Wright TM and John MR: Rapid and robust response of biochemical markers of bone formation to teriparatide therapy. Bone 45: 1053-1058, 2009.

40. Okuda T, Ioku K, Yonezawa I, Minagi H, Kawachi G, Gonda Y, Murayama H, Shibata Y, Minami S, Kamihira S, et al: The effect of the microstructure of beta-tricalcium phosphate on the metabolism of subsequently formed bone tissue. Biomaterials 28 : 2612-2621, 2007.

41. Okuda T, Ioku K, Yonezawa I, Minagi H, Gonda Y, Kawachi G, Kamitakahara M, Shibata Y, Murayama H, Kurosawa H and Ikeda T: The slow resorption with replacement by bone of a hydrothermally synthesized pure calcium-deficient hydroxyapatite. Biomaterials 29: 2719-2728, 2008

42. Gonda Y, Ioku K, Shibata Y, Okuda T, Kawachi G, Kamitakahara M, Murayama H, Hideshima K, Kamihira S, Yonezawa I, et al: Stimulatory effect of hydrothermally synthesized biodegradable hydroxyapatite granules on osteogenesis and direct association with osteoclasts. Biomaterials 30: 4390-4400, 2009.

43. Ikeda T, Kasai M, Suzuki J, Kuroyama H, Seki S, Utsuyama M and Hirokawa K: Multimerization of the receptor activator of nuclear factor-kappaB ligand (RANKL) isoforms and regulation of osteoclastogenesis. J Biol Chem 278: 47217-47222, 2003.

44. Parfitt AM, Drezner MK, Glorieux FH, Kanis JA, Malluche H, Meunier PJ, Ott SM and Recker RR: Bone histomorphometry: Standardization of nomenclature, symbols, and units. Report of the ASBMR Histomorphometry Nomenclature Committee. J Bone Miner Res 2: 595-610, 1987.

45. Daugaard H, Elmengaard B, Andreassen TT, Baas J, Bechtold JE and Soballe K: The combined effect of parathyroid hormone and bone graft on implant fixation. J Bone Joint Surg Br 93: 131-139, 2011.

46. Compston JE: Skeletal actions of intermittent parathyroid hormone: Effects on bone remodelling and structure. Bone 40: 1447-1452, 2007.

47. Leupold JA, Barfield WR, An YH and Hartsock LA: A comparison of ProOsteon, DBX, and collagraft in a rabbit model. J Biomed Mater Res B Appl Biomater 79: 292-297, 2006.

48. Castellani C, Zanoni G, Tangl S, van Griensven M and Redl H: Biphasic calcium phosphate ceramics in small bone defects: Potential influence of carrier substances and bone marrow on bone regeneration. Clin Oral Implants Res 20: 1367-1374, 2009.

49. Roberts WE, Turley PK, Brezniak N and Fielder PJ: Implants: Bone physiology and metabolism. CDA J 15: 54-61, 1987.

50. Johansson $C$ and Albrektsson T: Integration of screw implants in the rabbit: A 1-year follow-up of removal torque of titanium implants. Int J Oral Maxillofac Implants 2: 69-75, 1987.

51. Baker D, London RM and O'Neal R: Rate of pull-out strength gain of dual-etched titanium implants: A comparative study in rabbits. Int J Oral Maxillofac Implants 14: 722-728, 1999.

52. Dahlin C, Sennerby L, Lekholm U, Linde A and Nyman S: Generation of new bone around titanium implants using a membrane technique: An experimental study in rabbits. Int J Oral Maxillofac Implants 4: 19-25, 1989.

53. Mori H, Manabe M,Kurachi Y and Nagumo M: Osseointegration of dental implants in rabbit bone with low mineral density. J Oral Maxillofac Surg 55: 351-361, 1997. 
54. Pasquier G, Flautre B, Blary MC, Anselme K and Hardouin P Injectable percutaneous bone biomaterials: An experimental study in a rabbit model. J Mater Sci Mater Med 7: 683-690, 1996

55. Lu JX, Gallur A, Flautre B, Anselme K, Descamps M, Thierry B and Hardouin P: Comparative study of tissue reactions to calcium phosphate ceramics among cancellous, cortical, and medullar bone sites in rabbits. J Biomed Mater Res 42: 357-367, 1998.

56. Dodde R II, Yavuzer R, Bier UC, Alkadri A and Jackson IT: Spontaneous bone healing in the rabbit. J Craniofac Surg 11: 346-349, 2000.

57. Shimazaki K and Mooney V: Comparative study of porous hydroxyapatite and tricalcium phosphate as bone substitute. J Orthop Res 3: 301-310, 1985.

58. Eggli PS, Müller W and Shenk RK: Porous hydroxyapatite and tricalcium phosphate cylinders with two different pore size ranges implanted in the cancellous bone of rabbits. A comparative histomorphometric and histologic study of bony ingrowth and implant substitution. Clin Orthop Relat Res 127-138, 1988.

59. Uzawa T, Hori M, Ejiri S and Ozawa H: Comparison of the effects of intermittent and continuous administration of human parathyroid hormone(1-34) on rat bone. Bone 16: 477-484, 1995.

60. Hirano T, Burr DB, Cain RL and Hock JM: Changes in geometry and porosity in adult, ovary-intact rabbits after 5 months treatment with LY333334 (hPTH 1-34). Calcif Tissue Int 66: 456-460, 2000

61. Pettway GJ, Schneider A, Koh AJ, Widjaja E, Morris MD, Meganck JA, Goldstein SA and McCauley LK: Anabolic actions of PTH(1-34): Use of a novel tissue engineering model to investigate temporal effects on bone. Bone 36: 959-970, 2005.

62. Komatsubara S, Mori S, Mashiba T, Nonaka K, Seki A, Akiyama T, Miyamoto K, Cao Y, Manabe T and Norimatsu H: Human parathyroid hormone(1-34) accelerates the fracture healing process of woven to lamellar bone replacement and new cortical shell formation in rat femora. Bone 36: 678-687, 2005.

63. Corsini MS, Faraco FN, Castro AA, Onuma T, Sendyk WR and Shibli JA: Effect of systemic intermittent administration of human parathyroid hormone (rhPTH[1-34]) on the resistance to reverse torque in rabbit tibiae. J Oral Implantol 34: 298-302, 2008.
64. Yamamoto Y, Washimi Y, Kanaji A, Tajima K, Ishimura D and Yamada $\mathrm{H}$ : The effect of bisphosphonate and intermittent human parathyroid hormone 1-34 treatments on cortical bone allografts in rabbits. J Endocrinol Invest 35: 139-145, 2012.

65. Tanaka T, Komaki H, Chazono M and Fujii K: Use of a biphasic graft constructed with chondrocytes overlying a beta-tricalcium phosphate block in the treatment of rabbit osteochondral defects. Tissue Eng 11: 331-339, 2005.

66. Sugimoto T, Nakamura T, Nakamura Y, Isogai Y and Shiraki M: Profile of changes in bone turnover markers during once-weekly teriparatide administration for 24 weeks in postmenopausal women with osteoporosis. Osteoporos Int 25: 1173-1180, 2014.

67. Ikeda T, Yamaguchi A, Yokose S, Nagai Y, Yamato H, Nakamura T, Tsurukami H, Tanizawa T and Yoshiki S: Changes in biological activity of bone cells in ovariectomized rats revealed by in situ hybridization. J Bone Miner Res 11: 780-788, 1996.

68. Martin TJ and Sims NA: Osteoclast-derived activity in the coupling of bone formation to resorption. Trends Mol Med 11: 76-81, 2005.

69. Kondo N, Ogose A, Tokunaga K, Ito T, Arai K, Kudo N, Inoue H, Irie $\mathrm{H}$ and Endo $\mathrm{N}$ : Bone formation and resorption of highly purified beta-tricalcium phosphate in the rat femoral condyle. Biomaterials 26: 5600-5608, 2005.

70. Walker EC, McGregor NE, Poulton IJ, Pompolo S, Allan EH, Quinn JM, Gillespie MT, Martin TJ and Sims NA: Cardiotrophin-1 is an osteoclast-derived stimulus of bone formation required for normal bone remodeling. J Bone Miner Res 23: 2025-2032, 2008. Attribution-NonCommercial-NoDerivatives 4.0 International (CC BY-NC-ND 4.0) License. 